\title{
EROSIVIDADE DA CHUVA: SUA DISTRIBUIÇÃO E RELAÇÃO COM AS PERDAS DE SOLO EM CAMPINAS (SP) $\left.{ }^{1}\right)$
}

\author{
FRANCISCO LOMBARDI NETO $\left({ }^{2}\right)$ e WILLIAM CALVIN MOLDENHAUER $\left({ }^{3}\right)$
}

\begin{abstract}
RESUMO
O potencial de erosão de uma chuva, representado pelo produto da energia cinética pela intensidade máxima em $\mathbf{3 0}$ minutos, foi calculado para chuvas individuais, para Campinas (SP). Durante um período de 22 anos (de 1954 a 1975), o ínđice de erosăo médio anual computado foi de $6.738 \mathrm{MJ} . \mathrm{mm} / \mathrm{ha}$.h.ano, tendo os valores variado de 3.444 a 13.830 . Foram estabelecidas as distribuiçōes mensais e estacionais do índice de erosão. Os dados mostraram que $62 \%$ do potencial de erosăo anual ocorre durante dezembro-fevereiro. A freqüência de distribuição dos valores totais anuais e do valor máximo anual do índice de erosão seguiu o tipo de curva inclinada, típica de dados hidrológicos, mas o logaritmo dos dados apresentou distribuição normal. Foi encontrada alta correlaçăo entre a média mensal do índice de erosāo e a média mensal do coeficiente de chuva, o que simplifica o método para calcular o índice de erosão de um local.
\end{abstract}

Termos de indexaçāo: precipitação pluvial, coeficiente de chuva, erosão, equação de perdas de solo.

\author{
ABSTRACT \\ RAINFALL EROSIVITY - ITS DISTRIBUTION AND RELATIONSHIP \\ WITH SOIL LOSS AT CAMPINAS, STATE OF SÃO PAULO, BRAZIL
}

The rainfall erosion potential for individual storms was evaluated for Campinas, State of São Paulo, Brazil. The erosion potential of a rainstorm is the product of the rainfall energy and the maximum 30-minute intensity of the storm. Over a 22-year period the average annual erosion index computed was 6,738 MJ.mm/ha.h.year (values ranged from 3,444 to 13,830 ). Monthly and seasonal distributions of the erosion index were established. The data showed that $62 \%$ of the annual erosion potential occurs during the period from December to February. The frequency distribution of the total annual and maximum annual individual storm erosion index was skewed, but the logarithms of the data appeared to be normally distributed. Expected average monthly and annual values of erosion potential may be readily estimated from local rainfail amount records by the equation $\mathrm{EI}=68,730\left(\mathrm{p}^{2} / \mathrm{P}\right)^{0,841}$. A high correlation was found between actual and estimated EI values.

Index terms: rainfall, rainfall coefficient, universal soil loss equation, USLE.

\section{INTRODUÇÃO}

A expressão do potencial de erosāo de uma chuva refere-se à perda de solo por unidade de área que pode ser esperada de uma chuva caindo em área completamente desprovida de cobertura e resíduos vegetais, mas sofrendo os mesmos tipos de operaçōes culturais do solo cultivado. Por essa definição, o potencial de erosão de uma chuva é função do solo, do declive e das características da chuva.

Wischmeier \& Smith (1958) verificaram que, quando todos os outros fatores, com exceção da

(1) Recebido para publicação em 22 de outubro de 1991 e aceito em 23 de dezembro de 1992.

(2) Seção de Conservaçāo do Solo, Instituto Agronômico de Campinas (IAC), Caixa Postal 28, 13001-970 Campinas (SP).

$\left(^{3}\right)$ United State Department of Agriculture Science and Education Administration and Professor of Agronomy, Purdue University, West Lafayette, Indiana, USA. 
chuva, são mantidos constantes, a perda de solo por unidade de área de um terreno desprotegido de vegetação é diretamente proporcional ao produto de duas características da chuva: energia cinética multiplicada por sua intensidade máxima em $\mathbf{3 0}$ minutos. Essa foi a melhor correlação encontrada para expressar o potencial erosivo da chuva.

Hudson (1973), na África subtropical, observou que a energia cinética de chuvas individuais, com intensidades de $25,4 \mathrm{~mm}$ ou maiores, foi mais estreitamente correlacionada com as perdas de solo do que com qualquer outro parâmetro individual testado. A essa energia, o autor deu a designação de $\mathrm{KE}>25$.

Devido ao fato de que os registros de pluviógrafos são escassos ou inexistentes em países pouco desenvolvidos, além de as análises dos diagramas dos pluviógrafos para fins de cálculo da energia cinética serem extremamente morosas e trabalhosas, diversos autores tentaram correlacionar o índice de erosāo com fatores climáticos de mais fácil medida e que não requerem registros de intensidade de chuva.

No presente trabalho, procurou-se determinar: (a) a energia cinética e o índice de erosão para as chuvas individuais de Campinas; (b) as distribuiçōes anual, mensal e estacional do índice de erosão, e (c) a correlação entre perdas de solo e características de chuva.

\section{MATERIAL E METODOS}

Dados básicos de enxurrada, perdas de solo e precipitação foram reunidos no Centro Experimental de Campinas do Instituto Agronômico, no período de 1954-1975. Os dados de perdas de solo por erosão foram obtidos em talhões retangulares de $100 \mathrm{~m}^{2}$ (4 $\left.\times 25 \mathrm{~m}\right)$ de área útil e declive de $9,9 \%$, em latossolo roxo distrófico, A moderado, textura muito argilosa/argilosa, unidade Barāo de Geraldo (Typic Haplortox).

Nos diagramas de chuva, foram determinados, para todas as chuvas de $\mathbf{1 0} \mathbf{~ m m}$ ou maiores, e/ou chuvas menores de $10,0 \mathrm{~mm}$ que apresentaram perdas de solo e/ou enxurrada, a quantidade total, a duração, a energia cinética e a intensidade máxima de 30 minutos.

O procedimento adotado foi o estabelecido por Wischmeier (1959) e Wischmeier \& Smith (1958, 1978). A equação para calcular a energia cinética da chuva foi:

$$
\mathrm{Ec}=0,119+0,0873 \times \log \mathrm{I}
$$

onde:

$\mathrm{Ec}=$ energia cinética em megajoule por hectare-milímetro de chuva;

I = intensidade de chuva em milímetro por hora.

Considerando que as gotas de tamanho médio não continuam a aumentar quando a intensidade de chuva excede $76 \mathrm{~mm} / \mathrm{h}$, esse valor é o limite superior do campo de definição da variável I (Wischmeier \& Smith, 1978), sendo a energia cinética igual a 0,283 MJ/ha.mm.

$O$ índice de erosão, EI, foi calculado por:

$$
E I=E c \times I_{30}
$$

onde :

EI = índice de erosão em megajoule-milímetro por hectare-hora;

Ec = energia cinética em megajoule por hectare;

$I_{30}=$ intensidade máxima em $\mathbf{3 0}$ minutos, em milímetro por hora.

Os valores de EI para cada chuva individual foram somados mensalmente, anualmente ou por períodos que não envolvessem mudanças significativas nos efeitos do resíduo, cobertura e manejo ou condições físicas da área.

As determinações de perdas de solo foram obtidas durante o período de julho de 1957 a junho de 1972, para dois tipos de cobertura: solo descoberto e algodão contínuo.

O coeficiente de chuva foi determinado como proposto por Fournier (1960), com algumas modificaçōes:

$$
\mathrm{C}_{\mathrm{c}}=\mathrm{p}^{2} / \mathrm{P}
$$


onde:

$\mathrm{C}_{c}=$ coeficiente de chuva em milímetro;

p = precipitação média mensal em milímetro;

$\mathbf{P}=$ precipitação média anual em milímetro.

Análises de regressōes lineares simples e múltiplas foram realizadas, bem como a análise de probabilidade do índice de erosão, utilizando-se a lei de probabilidade logarítmica e a teoria dos valores extremos.

\section{RESULTADOS E DISCUSSÃO}

\subsection{Distribuição anual do potencial de erosão da chuva}

O fator erosividade da chuva (R) é definido como o índice de erosão da chuva de um local. Esse índice - uma avaliação numérica do valor médio anual da chuva de um local - expressa a capacidade daquela chuva de erodir o solo de um terreno desprotegido de vegetação.

$O$ índice anual médio de erosão encontrado para Campinas foi de 6.738 MJ.mm/ha.h.ano, com um desvio padrão de $2.423 \mathrm{MJ} . \mathrm{mm} / \mathrm{ha}$.h.ano e um erro de estimativa da média de 520 , e com coeficiente de variação de $35,8 \%$. Os valores para o período de 22 anos variaram de 3.444 a 13.830 MJ.mm/ha.h.ano (Quadro 1).

\subsection{Distribuição mensal do potencial de erosão da chuva}

A distribuição mensal do potencial de erosão foi encontrada somando-se os valores individuais de EI mensalmente por 22 anos. Pela figura 1 - médias mensais de precipitação e do índice de erosão para os 22 anos de dados para Campinas - verifica-se que $90,7 \%$ do índice anual de erosão ocorre de outubro a março, correspondendo a $80,1 \%$ do total anual de chuva. Para o período de dezembro-fevereiro, ocorre 62 e $50 \%$ do índice da erosāo anual e da precipitação anuais respectivamente, mostrando que nesses meses grande quantidade de perda de solo anual é esperada.
A distribuição mensal do índice de erosão foi expressa em porcentagem do valor anual, eliminando-se os valores extremos, isto é, o maior e o menor valor de EI de cada mês foi eliminado do cálculo da porcentagem, a fim de evitar que tendências de valores extremos se concentrassem em um mês. A porcentagem média mensal do EI total assim calculada encontra-se na figura 2 , que é a curva de distribuiçáo dessas porcentagens acumuladas a partir de $1^{\circ}$ de julho. Essa curva é importante no cálculo do fator uso-manejo (C) da equação de predição de perdas de solo.

\subsection{Frequêência de distribuição do potencial de crosão da chuva}

Segundo Wischmeier (1959), a freqüência de distribuição dos valores anuais do índice de erosão segue a distribuição log-normal, e os valores estacionais e mensais desse índice e valores máximos individuais anuais seguem o mesmo tipo de freqüência de distribuição.

Para as condições de Campinas, os valores anuais do índice de erosāo seguem a distribuição log-normal, como predita por Wischmeier (1959). A média anual do valor do EI encontrada foi de 6.738 MJ.mm/ha.h.ano, com variação de 3.444 a 13.830 MJ.mm/ha.h.ano, enquanto os valores do índice de erosāo, que sāo esperados excederem a média, um ano em 2, 5, 20 e 100 anos, foram 6.386, $8.495,11.173$ e 14.087 MJ.mm/ha.h.ano respectivamente.

Análise similar foi realizada para os valores máximos anuais do índice de erosão, encontrando-se, para o período de estudo, um valor máximo de 2.217 MJ.mm/ha.h.ano e um valor médio de 1.050 MJ.mm/ha.h.ano, e os períodos de retorno para 2, 5,20 e 100 anos, de $1.020,1.452,2.030$ e 2.707 MJ.mm/ha.h.ano respectivamente.

\subsection{Indice de erosăo e coeficiente de chuva}

Nas regiōes tropical e subtropical, a erosão é dependente da soma das dez ou vinte chuvas mais severas do ano. Isso concorda com os princípios contidos no índice de erosividade de Wischmeier e Smith (1958), o qual leva em conta o efeito com- 
Quadro 1. Valores mensais e anuais do índice de erosão para Campinas (SP)

\begin{tabular}{|c|c|c|c|c|c|c|c|c|c|c|c|c|}
\hline Mês & 54 & 55 & 56 & 57 & 58 & 59 & 60 & 61 & 62 & 63 & 64 & 65 \\
\hline Jan. & 1.315 & 1.805 & 304 & 2.394 & 1.167 & 481 & 903 & 2.148 & 353 & 4.130 & 216 & 991 \\
\hline Fev. & 883 & 863 & 755 & 1.001 & 647 & 265 & 422 & 1.530 & 647 & 3.345 & 3.473 & 1.187 \\
\hline $\mathbf{M}^{\text {co. }}$ & 226 & 461 & 2.227 & 2.345 & 510 & 255 & 559 & 549 & 1.707 & 206 & 29 & 314 \\
\hline Abril & 39 & 196 & 373 & 157 & 39 & 284 & 59 & 618 & 20 & 98 & 343 & 167 \\
\hline Maio & 98 & 78 & 461 & 0 & 461 & 0 & 137 & 0 & 0 & 0 & 29 & 128 \\
\hline Jun. & 10 & 0 & 20 & 196 & 451 & 0 & 265 & 0 & 20 & 0 & 49 & 0 \\
\hline Jul. & 0 & 0 & 255 & 206 & 0 & 0 & 0 & 0 & 10 & 0 & 59 & 78 \\
\hline Ag. & 0 & 137 & 88 & 78 & 0 & 314 & 20 & 0 & 49 & 0 & 0 & 0 \\
\hline Set. & 39 & 0 & 88 & 275 & 157 & 29 & 0 & 0 & 265 & 0 & 265 & 638 \\
\hline Out. & 69 & 530 & 186 & 206 & 88 & 383 & 883 & 88 & 412 & 824 & 775 & 903 \\
\hline Nov. & 392 & 39 & 49 & 579 & 402 & 942 & 49 & 981 & 422 & 1.059 & 481 & 952 \\
\hline Dez. & 383 & 903 & 471 & 628 & 383 & 491 & 1.118 & 2.217 & 1.393 & 314 & 2.374 & 1.275 \\
\hline Total & 3.454 & 5.012 & 5.277 & 8.065 & 4.305 & 3.444 & 4.415 & 8.131 & 5.298 & 9.976 & 8.093 & 6.633 \\
\hline
\end{tabular}

\begin{tabular}{lrrrrrrrrrrr} 
Mês & 66 & 67 & 68 & 69 & 70 & 71 & 72 & 73 & 74 & 75 & Média \\
\hline Jan. & 2.119 & 2.129 & 883 & 657 & 3.747 & 186 & 2.894 & 1.687 & 4.081 & 1.305 & 1.631 \\
Fev. & 667 & 2.482 & 951 & 1.089 & 5.189 & 412 & 2.659 & 1.275 & 559 & 1.530 & 1.447 \\
M so. & 1.521 & 471 & 1.246 & 167 & 1.599 & 1.707 & 29 & 333 & 510 & 98 & 776 \\
Abril & 108 & 59 & 383 & 177 & 20 & 491 & 530 & 29 & 78 & 206 & 203 \\
Maio & 186 & 59 & 88 & 157 & 127 & 118 & 98 & 88 & 0 & 10 & 106 \\
Jun. & 0 & 255 & 29 & 98 & 78 & 177 & 0 & 78 & 226 & 0 & 89 \\
Jul. & 0 & 0 & 0 & 10 & 0 & 20 & 255 & 177 & 0 & 59 & 51 \\
Ag. & 29 & 0 & 29 & 69 & 157 & 0 & 177 & 20 & 0 & 0 & 53 \\
Set. & 69 & 157 & 10 & 88 & 275 & 157 & 127 & 29 & 39 & 49 & 125 \\
Out. & 441 & 1.501 & 353 & 441 & 304 & 441 & 314 & 1.020 & 441 & 2.335 & 588 \\
Nov. & 157 & 1.589 & 49 & 1.442 & 392 & 422 & 598 & 177 & 667 & 834 & 576 \\
Dez. & 2.433 & 491 & 530 & 1.109 & 1.942 & 1.069 & 186 & 1.756 & 1.363 & 1.226 & 1.093 \\
Total & 7.730 & 9.193 & 4.551 & 5.504 & 13.830 & 5.200 & 7.867 & 6.669 & 7.964 & 7.652 & 6.738 \\
\hline
\end{tabular}

binado do total, da intensidade máxima e da duraçāo das chuvas. Todavia, a análise dos diagramas de chuva dos pluviógrafos é trabalhosa e morosa e, em certos países, tais diagramas são escassos ou inexistentes.
Numa tentativa para simplificar o método, foi feita uma regressão entre o índice médio mensal de erosão e o coeficiente de chuva, obtendo-se um alto coeficiente de determinação $\left(\mathrm{R}^{2}=0,983\right)$, conforme mostra a figura 3 , expresso pela equação: 
EROSIVIDADE DA CHUVA: SUA DISTRIBUIÇÃO E RELAÇÃO...

193

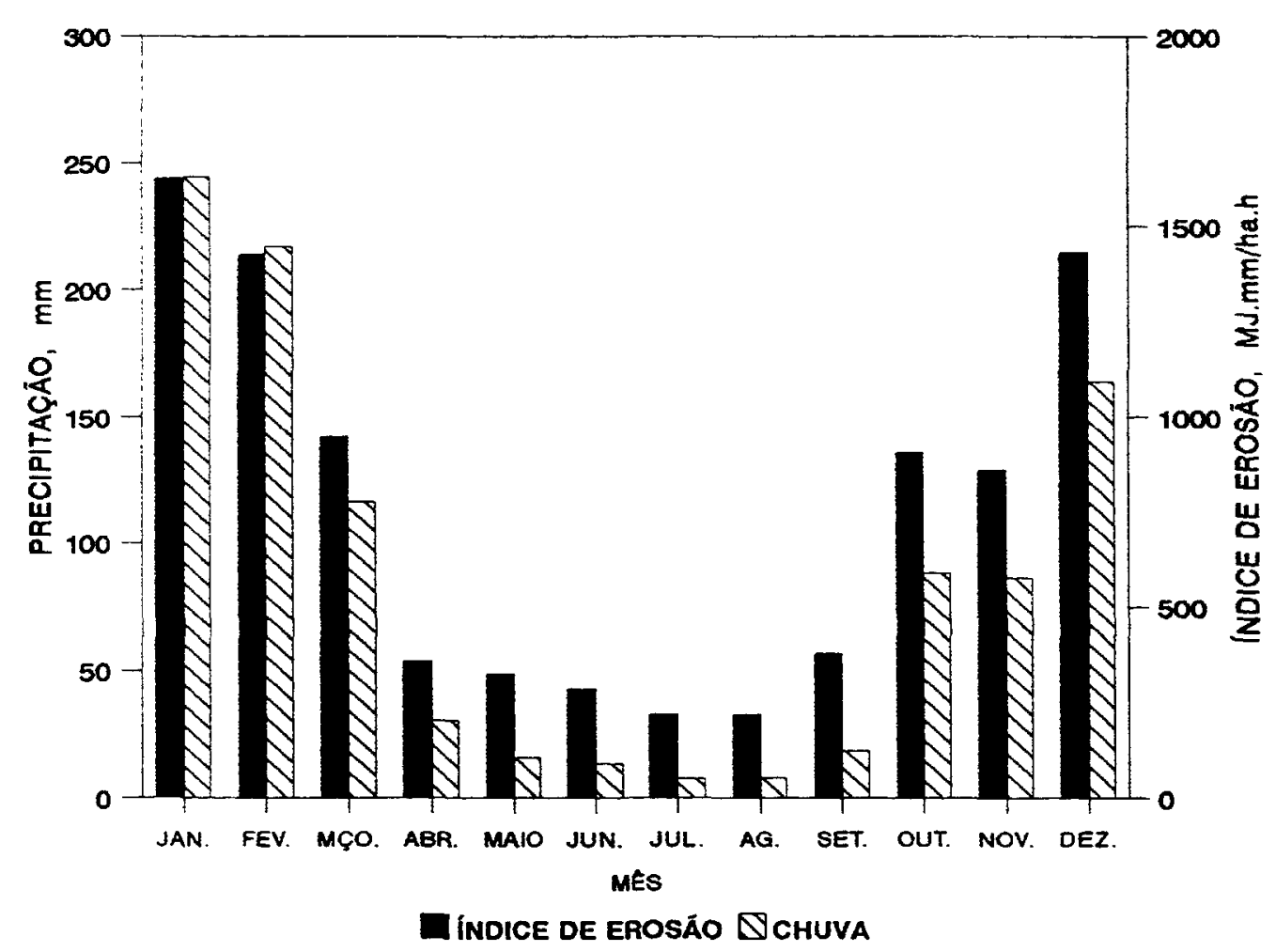

Figura 1. Médias mensais da precipitação pluvial e do índice de erosão para Campinas (22 anos de dados)

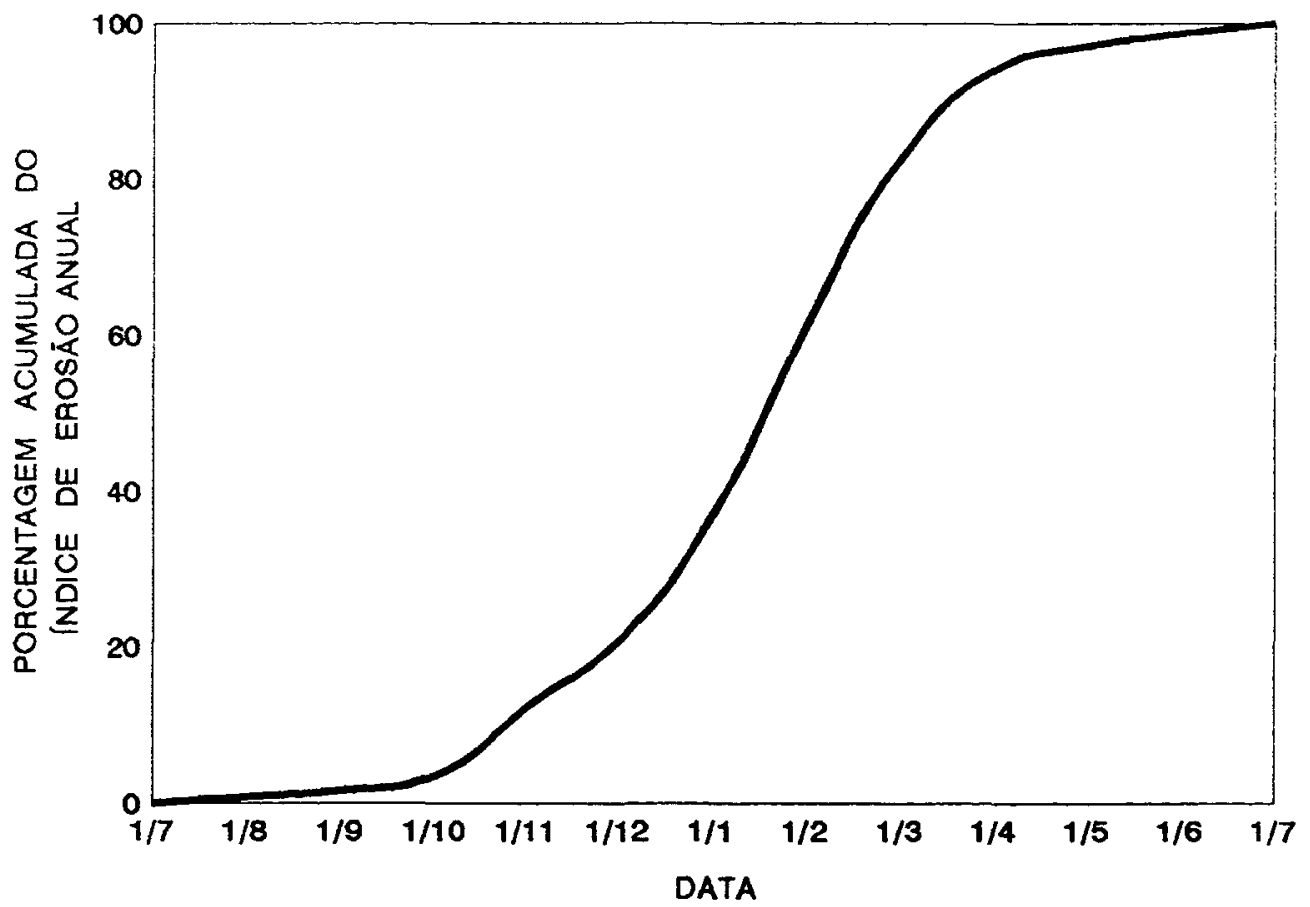

Figura 2. Curva de distribuição do índice de erosăo anual em Campinas

Bragantia, Campinas, 51(2):189-196, 1992 


$$
E I=68,730\left(p^{2} / P\right)^{0,841}
$$

onde:

EI = média mensal do índice de erosāo em MJ.mm/ha.h.ano;

p = precipitação média mensal em milímetro;

$\mathbf{P}=$ precipitação média anual em milímetro.

$O$ índice de erosão médio anual, isto é, o fator $\mathbf{R}$ para um local, é a soma dos valores mensais do índice de erosão. Para um longo período de tempo, vinte anos ou mais, essa equação estima, com relativa precisão, os valores médios de EI de um local, usando somente totais de chuva, disponíveis para muitos locais.

\subsection{Perdas de solo e características de chuva}

Correlações de perdas de solo para chuvas individuais com algumas características de chuva foram obtidas para o período de estudo. $O$ quadro 2 mostra os coeficientes de correlação encontrados para cerca de 650 chuvas analisadas.
Os dados mostram que o total de chuva e a energia cinética foram pobremente correlacionados com as perdas de solo. $A$ intensidade máxima em 30 minutos $\mathrm{e} o$ índice de erosão foram os melhores valores de correlações simples encontrados. Análises múltiplas de regressão não melhoraram a correlação. $O$ baixo valor para o coeficiente de correlaçāo para todas as variáveis analisadas pode ser devido ao rodízio que o talhāo descoberto sofria anualmente, com um efeito residual dos tratamentos anteriores influenciando as perdas de solo, principalmente durante o período de outubro a dezembro. O algodão contínuo foi plantado em contorno, sendo as perdas de solo reduzidas em vista do efeito do contorno.

3.6 Perdas de solo e valores de índice de erosão

A correlação entre a precipitação anual e os valores anuais de perdas de solo para os talhōes descoberto e com algodão contínuo mostrou-se muito pobre, ocorrendo o mesmo entre os valores de perdas de solo anuais e os valores anuais de índice de erosão.

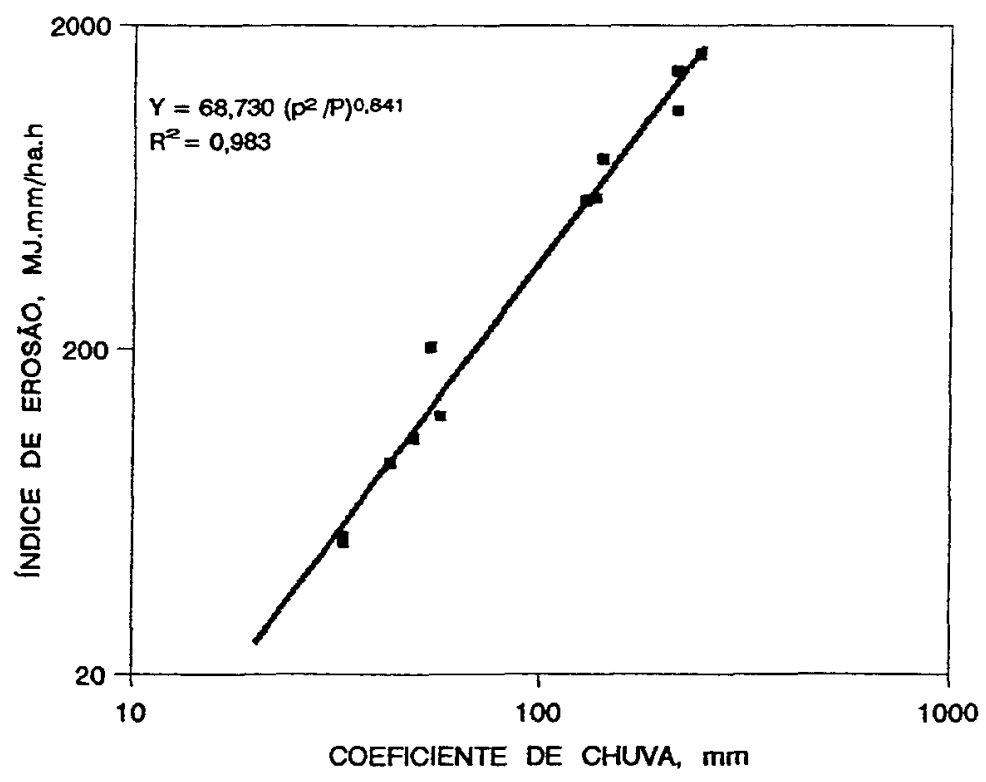

Figura 3. Regressão entre a média mensal do índice de erosão e o coeficiente de chuva em Campinas 
Quadro 2. Coeficientes de correlação entre características de chuva e perdas de solo, em latossolo roxo, para terreno descoberto e algodão contínuo, em Campinas (9,9\% de declive, 15 anos de dados)

\section{Variáveis}

Descoberto

Aigodão

contínuo

Precipitaçăo (P)

0,447

0,446

Energia cinética $(\mathrm{Ec})$

0,526

0,518

Intensidade máx. 30 min (I30)

0,643

0,672

0,559

0,584

fndice de erosão (EI)

$\mathrm{P}+\mathrm{Ec}$

0,645

$\mathrm{P}+\mathrm{I}_{30}$

0,686

0,668

$\mathrm{Ec}+\mathrm{EI}$

0,691
Quando o índice de erosão mensal foi correlacionado com perdas mensais de solo, para o talhão descoberto, um coeficiente de correlação de $\mathbf{0 , 8 2 2}$ foi encontrado.

As figuras 4 e 5 mostram a correlaçāo entre a média mensal de perdas de solo e a média mensal do índice de erosão para quinze anos de dados para o solo descoberto e com algodão contínuo respectivamente, as quais apresentaram maior correlação que os valores individuais e que $95 \%$ do total de variação nas perdas médias mensais de solo pode ser explicada pelo índice de erosão médio mensal.

$O$ fato de que as perdas médias de solo para um longo período de tempo podem ser estimadas dentro de limites de confidências relativamente estreitos, com base nos valores de EI, não implica que as perdas de solo para chuvas específicas ou anos específicos possam ser estimadas com igual precisão.

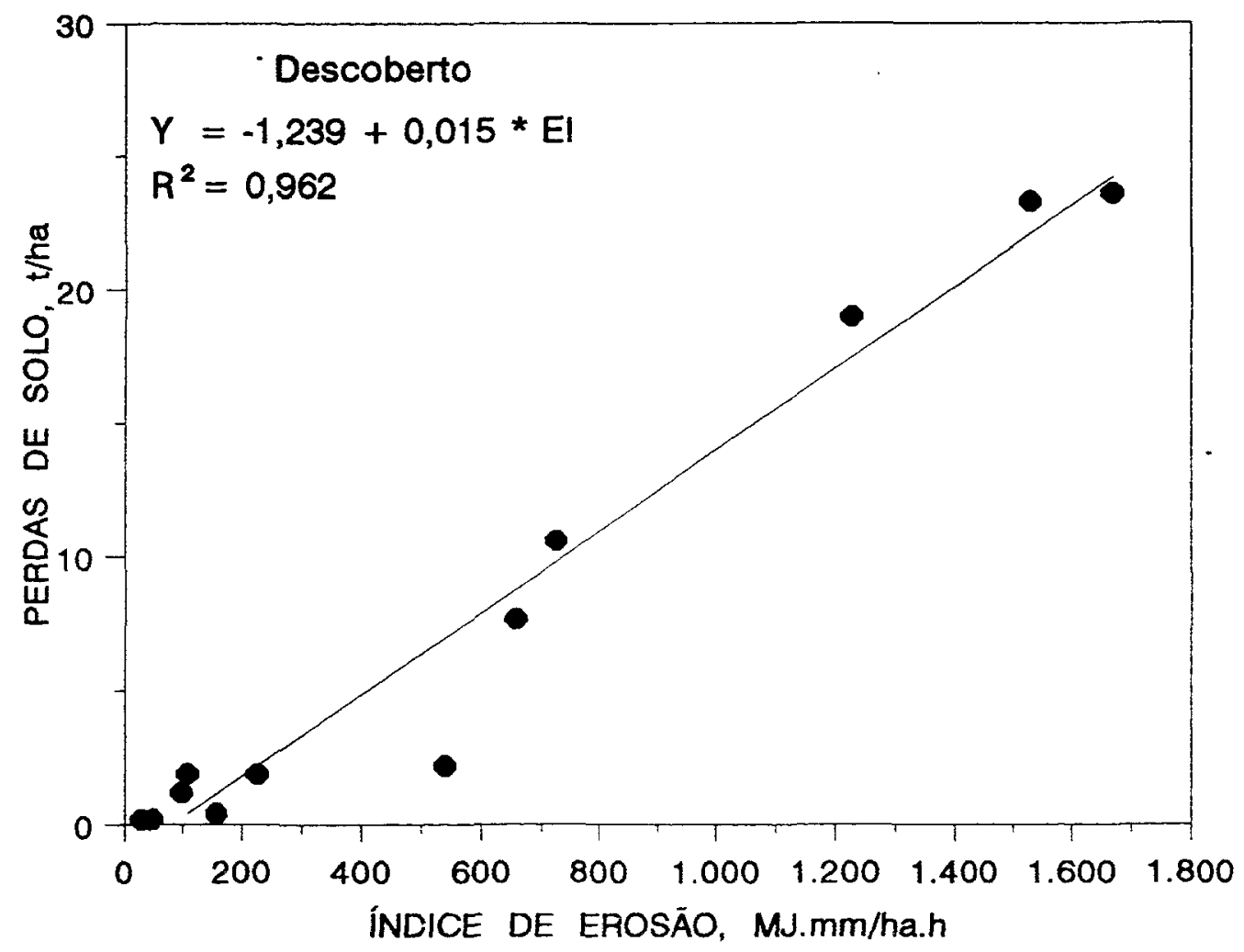

Figura 4. Regressão entre a média mensal de perdas de solo e a média mensal do índice de erosão, para solo descoberto, em latossolo roxo. Campinas. 


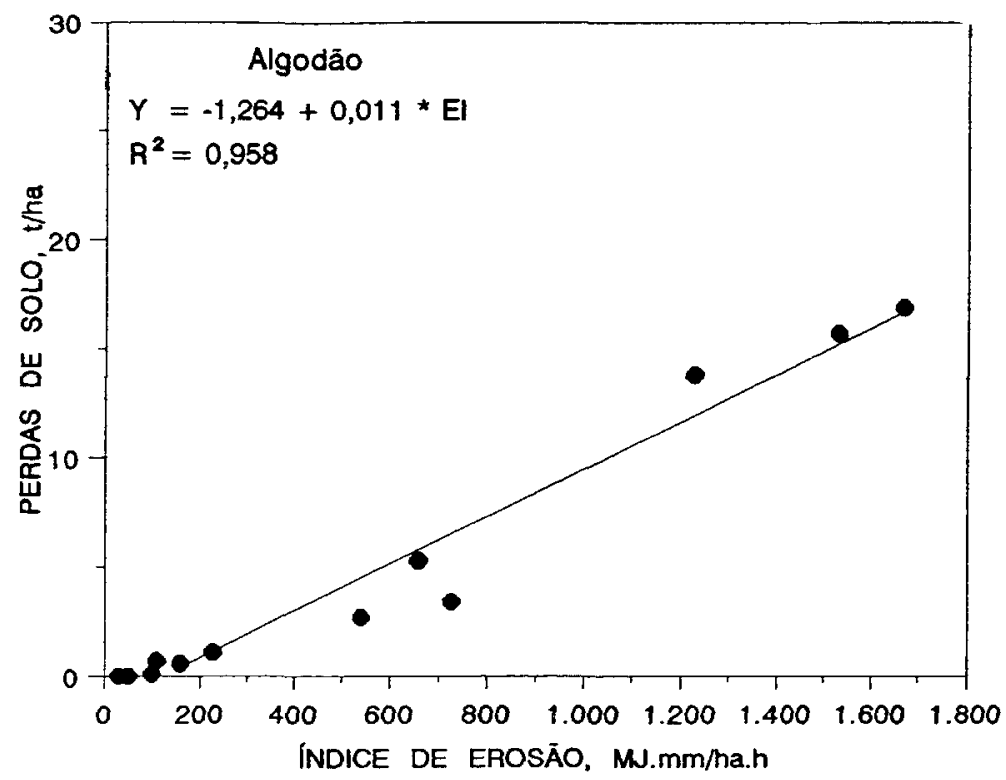

Figura 5. Regressão entre a média mensal de perđas de solo e a média mensal do índice de erosão, para a cultura algodåo contínuo, em latossolo roxo. Campinas.

\section{CONCLUSÖES}

1. Durante o período de 22 anos (1954-1975), o índice de erosão médio anual (erosividade) para Campinas foi de $6.738 \mathrm{MJ} . \mathrm{mm} / \mathrm{ha}$.h.ano, tendo os valores variado de 3.444 a $13.830 \mathrm{MJ} . \mathrm{mm} / \mathrm{ha} . \mathrm{h}$. ano.

2. Os resultados obtidos mostram que $62 \%$ do potencial de erosão anual ocorre no período de dezembro-fevereiro.

3. Houve boa correlação $\left(R^{2}=0,983\right)$ entre o coeficiente de chuva $\mathrm{e} o$ índice de erosão.

4. Houve boa correlação entre as perdas de solo e o índice de erosão, sendo $\mathbf{R}^{2}=0,964$ para o solo descoberto e $R^{2}=0,958$ para o solo com cultura de algodão.

\section{REFERÊNCIAS BIBLIOGRÁFICAS}

FOURNIER, F. Climat et erosion. Paris, Press Universitaries de France, 1960. 201p.

HUDSON, N. Soil conservation. 2.ed. Ithaca, Cornell University Press, 1973. 320p.

WISCHMEIER, W.H. A rainfall erosion index for a Universal Soil-Loss Equation. Soil Science Society of America Proceedings, Madison, 23(3):246-249, 1959.

WISCHMEIER, W.H. \& SMITH, D.D. Rainfall energy and its relationship to soil loss. Transactions American Geophysical Union, Washington, D.C., 39(2):285-291, 1958.

WISCHMEIER, W.H. \& SMITH, D.D. Predicting rainfall erosion losses: a guide to conservation planning. Washington, D.C., United States Department of Agriculture, 1978. 58p. (Agriculture handbook, 537) 